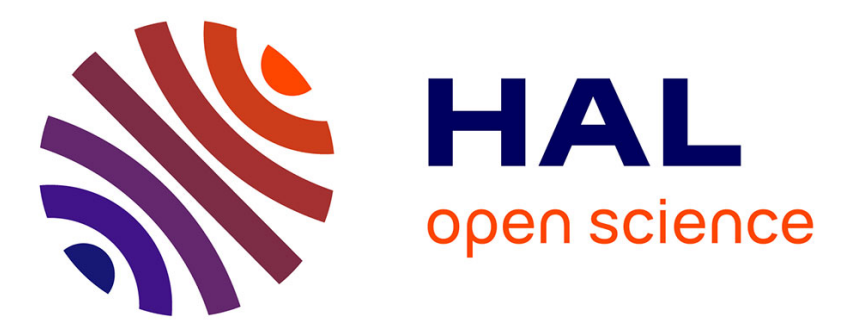

\title{
Computational modelling of epithelial to mesenchymal transition
}

Tariq Abdulla, Ryan Imms, Jean-Louis Dillenseger, Jean-Marc Schleich, Ron Summers

\section{> To cite this version:}

Tariq Abdulla, Ryan Imms, Jean-Louis Dillenseger, Jean-Marc Schleich, Ron Summers. Computational modelling of epithelial to mesenchymal transition. Innovation and Research in BioMedical engineering, 2011, 32 (5), pp.306-310. 10.1016/j.irbm.2011.09.001 . inserm-00745327

\section{HAL Id: inserm-00745327 https://www.hal.inserm.fr/inserm-00745327}

Submitted on 26 Oct 2012

HAL is a multi-disciplinary open access archive for the deposit and dissemination of scientific research documents, whether they are published or not. The documents may come from teaching and research institutions in France or abroad, or from public or private research centers.
L'archive ouverte pluridisciplinaire $\mathbf{H A L}$, est destinée au dépôt et à la diffusion de documents scientifiques de niveau recherche, publiés ou non, émanant des établissements d'enseignement et de recherche français ou étrangers, des laboratoires publics ou privés. 


\title{
Computational Modelling of Epithelial to Mesenchymal Transition
}

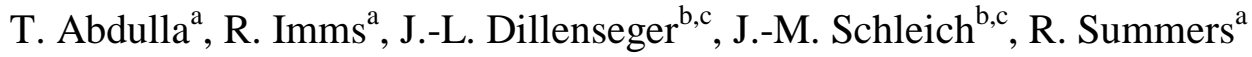 \\ ${ }^{a}$ Research School of Systems Engineering, Loughborough University, Loughborough, UK \\ bINSERM, U642, Rennes, F-35000, France \\ ${ }^{\mathrm{c}}$ Université de Rennes 1, LTSI, Rennes, F-35000, France
}

\begin{abstract}
Cell behaviour during epithelial to mesenchymal transition (EMT) was simulated using the cellular Potts formalism in Compucell3D. A recent in vitro study revealed that the mechanism of endocardial scattering can be induced independently of invasion into the extracellular matrix (ECM). This suggests that loss of endocardial cohesion alone is not sufficient for full EMT. The 3D simulations, which take account of changes in adhesion, match this conclusion. The principle by which the rate of mitosis regulates the endocardial monolayer was demonstrated; suggesting a route by which VEGF might regulate EMT.
\end{abstract}

Keywords

Heart Development, Simulation, EMT, Heart Valve

\section{Résumé}

Le comportement cellulaire durant la transformation épithélio-mésenchymateuse a été simulé en utilisant le modèle de Potts de Compucell 3D. Une récente étude in vitro a révélé que le mécanisme de fragmentation endocardique peut être induit indépendamment de l'invasion cellulaire dans la matrice extracellulaire. Cette observation suggère que la seule perte de cohésion endocardique n'est pas suffisante pour une transformation épithélio-mésenchymateuse complète. Les simulations 3D, qui tiennent compte des changements d'adhésion, s'accordent avec cette conclusion. Le principe que la fréquence des mitoses régule la couche endocardique ayant été démontré, celà suggére un lien par lequel le VEGF pourrait réguler la transformation épithélio-mésenchymateuse.

\section{Mots clés}

Développement cardiaque, simulation, transformation épithélio-mésenchymateuse, valve cardiaque

\section{Introduction}

Epithelial to mesenchymal transition (EMT) is a process by which epithelial cells lose their cohesion, migrate into the extracellular matrix (ECM) and adopt a mesenchymal phenotype. EMT remains poorly understood, though it is a crucial process in many areas of embryonic development. In heart development, EMT gives rise to the valves and membranous septa. An improved understanding of the process would be applicable to the aetiology of the majority of congenital heart defects. It would also apply to regenerative medicine, as the pathways that control endocardial EMT can be reactivated in adult tissue [1]. The importance of EMT has led to an array of in vivo and in vitro research efforts to develop a caricature of the protein and genetic interaction involved (Fig. 1).

With respect to Fig. 1, in the cushion forming regions myocardium secretes BMP2 and TGF $\beta$. These proteins are inhibited outside of the cushion forming regions by notch signalling. Endocardium within the regions is Notch1 active. Notch1 activates Snail family transcription factors, which downregulate the adhesion protein VE-cadherin. BMP and TGF $\beta$ activate Notch and Snaill via Smad signalling. The combination of these mechanisms stimulates EMT. The interaction of VEGF and NFAT control endocardial and mesenchymal proliferation. High VEGF acts to inhibit EMT, and the hypothesis that this could be due to increased endocardial proliferation maintaining the monolayer is investigated in this study.

$<<<$ Fig. $1>>>$

Fig.1: Major protein interactions during EMT in endocardial cushion growth in the atrioventricular canal (AVC) and the outflow tract (OFT).

A recent in vitro study of endocardial cells cultured on a collagen gel demonstrated that 2D scattering of cells on the surface could be induced independently of 3D invasion into the gel [2]. This was achieved by constitutively activating Notch1 in the cells, without treatment of BMP2 or TGF 32 . Treatment with TGF $\beta 2$ led to the similar $2 \mathrm{D}$ scattering, and anti-TGF $\beta 2$ both counteracted this and maintained the monolayer in Notch1 activated cells. Treatment with BMP2 induced both 2D and 3D invasiveness of wild type cells. This suggests that both TGF $\beta$ and Notch1 in endocardium act to reduce endocardial cohesion, independently of factors that 
induce 3D invasion (including increased endocardial-matrix adhesion).

\section{Methods}

Cellular Potts models (CPMs) are lattice based simulations, with cells occupying multiple sites on the lattice. In contrast to most other types of agent based modelling, this allows cells to have shape and size and surfaces that may be adjacent with other cells. According to the Differential Adhesion Hypothesis (DAH) morphogenetic changes are driven by cell displacements that lead to the lowest energy configurations, and thus the largest number of strong adhesive bonds. This can be simulated using the Metropolis Monte Carlo algorithm. A Hamiltonian energy, $H$, is defined for the system. During each step in the simulation, a random copy attempt is made for each lattice site at a cell surface. For each copy attempt the resulting change in energy, $\Delta H$, is calculated, and the copy attempt is accepted with a probability $\min \left(1, e^{\Delta H / T}\right)$; where $T$ is used as an intrinsic measure of cell motility. Thus motile cells in a CPM will tend to move so as to reduce $H$, reducing the entropy of the system. Typically the Hamiltonian equation includes terms for type dependent surface energies between each pair of different cell types. This represents their level of adhesion. Higher surface energy represents a lower level of adhesion. CPM can be extended to include terms for anything that can be calculated from the cell attributes. For example, a type dependent target volume or target surface area can be included, with values for the propensity of a cell to reach the target. Apoptosis (i.e. cell death) is generally simulated by setting a cell's target volume to zero. Mitosis can be simulated by creating daughter cells in place of the parent cell. Multiple fields can be defined across the same lattice, so secretion of a protein from cell surfaces can be simulated, as well as chemotaxis (movement of a cell towards a chemical stimulus). One of the simplest cellular Potts simulations represents a cell sorting experiment, where an initial mixed population of two or more cell types become sorted (see Fig. 2). The cells with higher preferential cohesion move to the centre of the cluster, while those with lower cohesion move to outer layers.

$\langle<\langle$ Fig.2 a) b) $>>>$

Fig.2: Cells interact at their surfaces (adjacent lattice sites) in cellular Potts models. a) At the start of the simulation, cell types are mixed. b) After 8000 Monte Carlo Steps (MCS), the cells are sorted, with the less cohesive type forming an outer layer.

CPMs are able to simulate cell behaviour by representing any mechanism where cell rearrangement is determined principally by differences in adhesion. As the focus of CPM is cell rearrangement, they have been used mainly for modelling developmental mechanisms. Compucell3D [3] is the most widely used modelling environment for implementation of CPMs. It is an open source resource and extensible, enabling the sharing of results.

Compucell3D simulations were created to represent in vitro EMT in 3D, with endocardial cells (EC) initially lying on the surface of extracellular matrix (ECM). The default 'medium' was treated as the space above the culture, with no intrinsic surface energy. An assumption is that EC-EC adhesion is stronger in the wild type situation (i.e. natural situation) than EC-ECM adhesion, and that the latter is stronger than ECM-ECM adhesion. The contact energy with the surrounding space is taken to be higher between the ECmedium than the ECM-medium, as cell membranes are less deformable than ECM. Therefore, to simulate wild type endocardial cells on the surface of ECM the following energy hierarchy is assumed:

$$
\mathrm{J}_{\mathrm{EC} \text {,medium }}>\mathrm{J}_{\mathrm{ECM}, \text { medium }}>\mathrm{J}_{\mathrm{ECM}, \mathrm{ECM}}>\mathrm{J}_{\mathrm{EC}, \mathrm{EC}}>\mathrm{J}_{\text {medium,medium }}=0
$$

From simulation it was found that the corresponding parameters of set 1 (Table I) give rise to an endocardial monolayer that does not invade the ECM. Set 2 corresponds to a loss of endocardial cohesion (increase in $\mathrm{J}_{\mathrm{EC}, \mathrm{EC}}$ ). Set 3 corresponds to a gain in EC-ECM adhesion (reduction in $\left.\mathrm{J}_{\mathrm{EC}, \mathrm{ECM}}\right)$. Set 4 corresponds to both effects simultaneously.

A more abstract scenario was used for investigating mitosis. An endocardial monolayer was defined as occupying the entire midplane between two layers of default medium. Surface energy parameters were adapted so that the medium would represent ECM (Table II). The mechanisms by which epithelial cells in a monolayer regulate mitosis are not precisely known. For the simulations, it was assumed that mitosis is regulated by some form of contact inhibition. The Compucell3D NeighbourTracker plugin and Mitosis stoppable were adapted such that a simulated cell will undergo mitosis if it meets the condition that the surface area it shares with the medium is greater than the surface area it shares with other endocardial cells. Cells were also required to have a volume greater than 200 voxels, in order to prevent excessive mitosis of small cell fragments.

\begin{tabular}{l|l|l|l|l|l|l|}
\hline $\begin{array}{l}\text { Surface } \\
\begin{array}{l}\text { Energy } \\
J\end{array}\end{array}$ & $\begin{array}{l}\text { EC, } \\
\text { Medium }\end{array}$ & $\begin{array}{l}\text { ECM, } \\
\text { Medium }\end{array}$ & $\begin{array}{l}\text { ECM, } \\
\text { ECM }\end{array}$ & $\begin{array}{l}\text { EC, } \\
\text { ECM }\end{array}$ & $\begin{array}{l}\text { EC, } \\
\text { EC }\end{array}$ & $\begin{array}{l}\text { Medium, } \\
\text { Medium }\end{array}$ \\
\hline Set 1 & 16 & 14 & 8 & 4 & 2 & 0 \\
Set 2 & 16 & 14 & 8 & 4 & 10 & 0 \\
Set 3 & 16 & 14 & 8 & 1 & 2 & 0 \\
Set 4 & 16 & 14 & 8 & 1 & 10 & 0 \\
\hline \hline
\end{tabular}

TABLE I: Surface energy parameters $J$, in $10^{-15} \mathrm{Kg}^{1} \mathrm{~s}^{-2}$. KEY: EC-Endocardial Cell; ECM-Extra Cellular Matrix

\begin{tabular}{l|l|l|l|}
\hline Surface Energy $J$ & EC, Medium & $\begin{array}{l}\text { EC, } \\
\text { EC }\end{array}$ & $\begin{array}{l}\text { Medium, } \\
\text { Medium }\end{array}$ \\
\hline Set A & 16 & 2 & 0 \\
Set B & 4 & 10 & 0 \\
Set C & 2 & 2 & 0 \\
Set D & 2 & 10 & 0 \\
\hline \hline
\end{tabular}

TABLE II: Surface energy parameters for mitosis simulations.

Simulated endocardial cells were assigned target volumes of 400 voxels and a fairly high volume constraint value of 20 , which ensured a consistent volume and rounded morphology typical of epithelial cells. $H$ is given by:

$$
\begin{aligned}
& H=H_{\text {Boundary }}+H_{\text {Volume }} \\
& \begin{aligned}
H=\sum_{\mathrm{i}, \mathrm{j}} \mathrm{J}[\tau\{\sigma(\overline{\mathrm{l}})\}, & \tau\{\sigma(\overline{\mathrm{j}})\}][1-\delta\{\sigma(\overline{\mathrm{l}}), \sigma(\overline{\mathrm{j}})\}] \\
& +\sum_{\sigma} \lambda_{\text {vol }}(\sigma)\left[v(\sigma)-V_{t}(\sigma)\right]^{2}
\end{aligned}
\end{aligned}
$$


Where for cell $\sigma, \lambda_{v o l}$ is the volume constraint, $V_{t}$ is the target volume, and for neighbouring lattice sites $\overline{\mathrm{l}}$ and $\overline{\mathrm{j}}, \mathrm{J}$ is the boundary coefficient between two cells $\left(\sigma, \sigma^{\prime}\right)$ of given types $\tau(\sigma), \tau\left(\sigma^{\prime}\right)$, and the boundary energy coefficients are symmetric:

$J\left[\tau(\sigma), \tau\left(\sigma^{\prime}\right)\right]=J\left[\tau\left(\sigma^{\prime}\right), \tau(\sigma)\right]$, and the Kronecker delta is $\delta_{x, y}=\{1, x=y ; o, x \neq y\}$.

\section{Results}

The base case scenario (Fig 3a) uses parameters from set 1 (Table 1) and was perturbed by adopting the parameters in sets 2-4 and running the simulation for a further 1000 MCS in separate experiments.

With set 2, ECs scattered on the surface of the matrix without invading it (Fig. 3b). With set 3, the ECs invaded the ECM, but without delaminating from each other (results not shown). With set 4, all ECs delaminated from each other, and some invaded the matrix (Fig. 3c).

$\langle<<$ Fig3 a) b) c) $\gg>$

Fig.3: CPM simulations of in vitro EMT. a) Endothelial monolayer on the surface of collagen gel. b) With reduced EC-EC adhesion, cells scatter on the surface, but do not invade the gel. c) With reduced EC-EC adhesion and increased EC-ECM adhesion, some cells invade the matrix (full EMT).

The mitosis scenarios were analogous to these results. Without mitosis, set A maintained the monolayer, while set B caused the cells to delaminate from one another in $2 \mathrm{D}$, set $\mathrm{C}$ caused them to cluster together in the medium and set D caused 3D invasion after 1000 MCS. The inclusion of contactinhibited mitosis caused the endothelial monolayer to prevail under set B and C, as each daughter cell would inherit a target volume of 400 voxels, causing the endothelial layer to rapidly replace gaps (Fig. 4). The monolayer failed under the conditions of set $\mathrm{D}$, and endocardial cells quickly fill the entire lattice, due to the conditions for mitosis specified (not shown). In this model, mitosis prevents breakdown of the monolayer for reduced EC-EC adhesion or increased EC-ECM adhesion separately, but not in combination.

$\langle<<$ Fig.4: a) b) c) d) $>>>$

Fig.4: Mitosis simulations. a) Cells separate in 2D under set B. b) Monolayer prevails under set $B$ if mitosis is included. c) Cells migrate in $2 \mathrm{D}$ and $3 \mathrm{D}$ under set $\mathrm{C}$. d) Including mitosis rescues monolayer integrity for set $\mathrm{C}$. Daughter cells are illustrated in a different shade.

Although in this simulation mitosis is treated as a lumped variable that occurs instantaneously, the results demonstrate a plausible mechanism by which VEGF could control the level of EMT. EMT ceases in the endocardial cushions as VEGF expression increases, and this could be due to an increase in the level of endocardial contact-inhibited mitosis.
The CPM simulations demonstrate some correspondence with the in vitro experiments on which they are based. In both the in vitro experiments and the simulations it was possible to induce 2D scattering of endocardial cells independently of 3D invasion into the ECM. In the in vitro experiment this was accomplished through Notch activation of the endocardium. Alongside simulation results, this supports the hypothesis that Notch primarily acts to reduce endocardial cohesion.

In the simulation with set 3 , it was possible for the endocardial cells to invade the matrix, but still remain attached together. This effect has not been observed in any in vitro experiments. This could be because it is not possible to isolate an increase in EC-ECM adhesion from a decrease in EC-EC adhesion, due to the nature of the signalling pathways. Notch is downstream of BMP signalling, and therefore inducing increased EC-ECM adhesion via introducing BMP would additionally reduce EC-EC adhesion (Fig. 1).

The simulations also indicated a possible role of contactinhibited mitosis in controlling EMT, which would provide an explanation for EMT restriction at high levels of VEGF. This hypothesis can be tested in vitro, which will provide further refinement for the model.

\section{Conflict of interests}

The authors declare that they have no conflict of interests concerning this article.

\section{Acknowledgements}

The authors thank Randy Heiland and Maciek Swat of the Biocomplexity Institute, Indiana University, for user support and guidance with the Compucell3D simulation environment.

\section{References}

[1] Yang J, Wylie-Sears J. Opposing actions of Notch1 and VEGF in post-natal cardiac valve endothelial cells. Biochemical and Biophysical Research Communications 2008;374:512-6.

[2] Luna-zurita L, Prados B, Grego-bessa J, Luxán G, Monte G, Benguría A et al. Integration of a Notch-dependent mesenchymal gene program and Bmp2-driven cell invasiveness regulates murine cardiac valve formation. J Clin Invest 2010;120:3493-507.

[3] Swat M H, Hester SD, Heiland RW, Zaitlen BL, Glazier JA. Multi-cell simulations of development and disease using the Compucell3D simulation environment. Methods Mol Biol 2009;500:361-428.

\section{Conclusion}


Figure 1

Endocardium

(Notch expression)

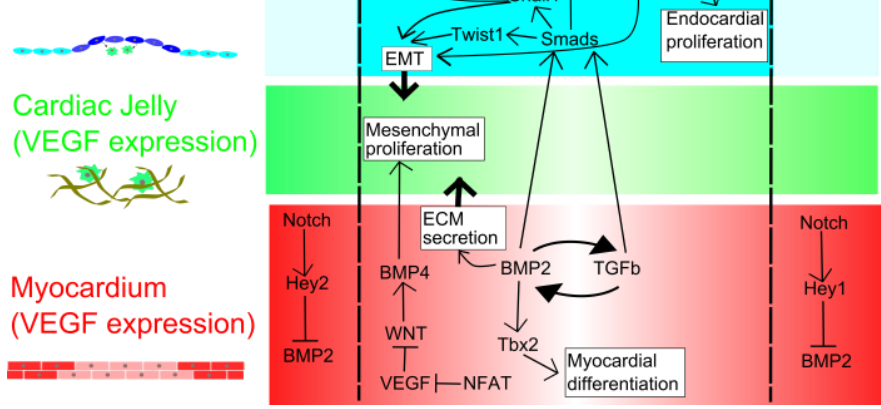

Figure 2

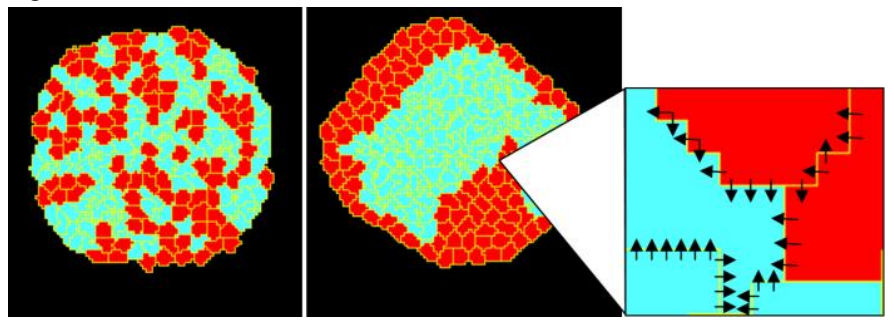

Figure 3
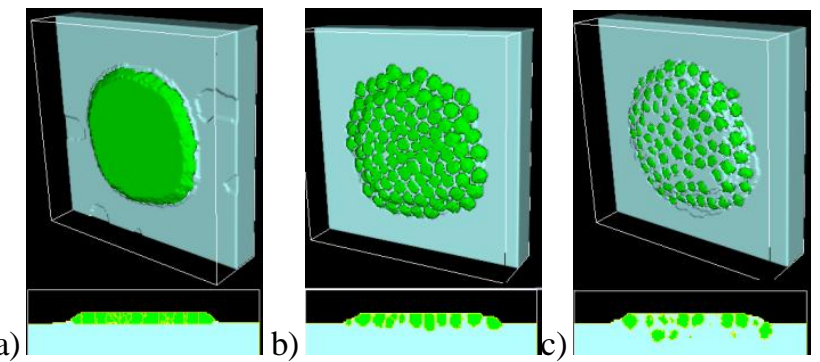

Figure 4

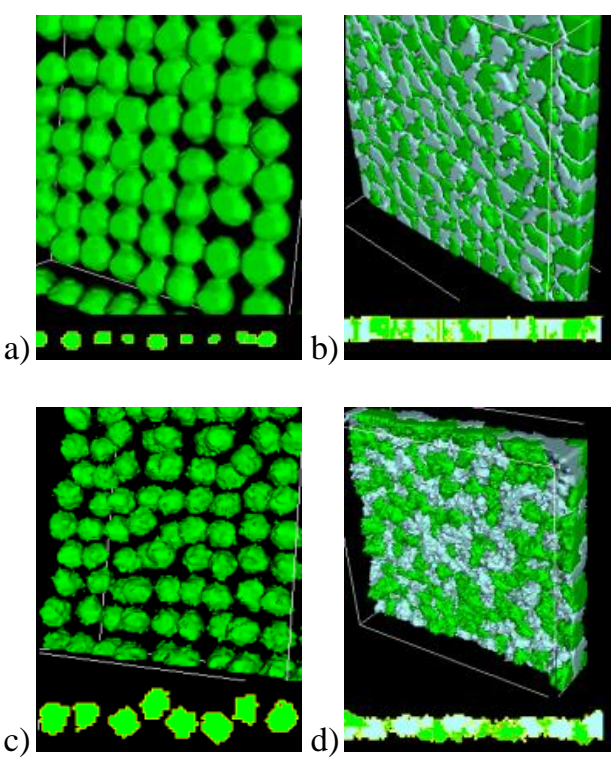

